\title{
Overview of Biotechnology research activities at the Biotechnology graduate program Rania Siam $1,2,3$
}

\author{
Address: ${ }^{1}$ Biotechnology Graduate Program, American University in Cairo, Cairo, Egypt, ${ }^{2}$ Biology Department, American University in Cairo, \\ Cairo, Egypt and ${ }^{3}$ YJ-Science and Technology Research Center, American University in Cairo, Cairo, Egypt \\ from 2009 American University in Cairo Research Conference \\ Cairo, Egypt. 5 April 2009
}

Published: I July 2009

BMC Proceedings 2009, 3(Suppl 3):O6

This abstract is available from: http://www.biomedcentral.com/I753-656I/3/S3/O6

(c) 2009 Siam; licensee BioMed Central Ltd.

The Biotechnology graduate program at the American University in Cairo was established in fall 07 to offer a contemporary scientific program in the fast paced field of Biotechnology. Current students in the program are performing cutting edge research that is essential for Egypt and the region. This talk is aimed to provide a general overview of the different research activities in the program, with emphasis on biomedical projects. These research projects includes, but is not limited to:

-Genetic variations and molecular disease discovery of an isolated community in Egypt.

-Molecular and genomic approach to investigate links between infectious diseases and cancer development.

-Metagenomic studies of marine organisms in the Red Sea.

-Comparative metabolic profiling of selected biological systems.

-Development and characterization of novel antibodybased as well as molecular diagnostic tests for detection of tumor biomarkers and infectious diseases.

-Therapeutic and diagnostic applications of nanotechnology.

-Early prediction of tumorogenic changes in cell cycle genes in Hepatitis C.

-Using optical traps to study the mechanical properties of biological polymers.
-Improving durability of biomedical implants through deposition of nanomaterials and nanocomposite thin film using various techniques.

-Fabrication of sensors and MEMS/NEMS for controlling the biological function of the various organs of the body.

State of the art facilities at the American University in Cairo, including the YJ-Science and Technology Research center have provided the foundations for the ongoing research projects. The metagenomics projects on unexplored marine environment in the Red Sea will be addressed in particular the emphasis on biotechnology applications will be addressed. 